\title{
Biosafety Assessment of Transgenic Plants in the Greenhouse and the Field -A Case Study of Transgenic Cucumber-
}

\author{
Yasunori KOGA-BAN ${ }^{*}$, Yutaka TABEI ${ }^{1}$, Masao ISHIMOTO ${ }^{2}$, \\ Yoko NISHIZAWA ${ }^{1}$, Kenichi TSUCHIYA ${ }^{3}$, Nobuyuki IMAIZUMI ${ }^{1}$, \\ Hidemitsu NAKAMURA ${ }^{1}$, Toshiaki KAYANO ${ }^{1}$ and Hiroshi TANAKA ${ }^{4}$ \\ 1,3,4 Plant Biotechnology Department, National Institute of Agrobiological Sciences \\ (Tsukuba, Ibaraki 305-8602, Japan) \\ ${ }^{2}$ National Agricultural Research Center (Tsukuba, Ibaraki 305-8666, Japan)
}

\begin{abstract}
We have developed transgenic cucumber plants Cucumis sativus L. resistant to gray mold (Botrytis cinerea) by the expression of rice chitinase cDNA (Tabei et al. 1998). These transgenic plants were obtained by Agrobacterium-mediated transformation, and the introduced rice chitinase cDNA was driven by the CaMV $35 \mathrm{~S}$ promoter. The biosafety assessment of the transformed cucumber plants was carefully performed to confirm that their characteristics are equivalent to those of non-transgenic plants except for harboring gray mold resistance. The biosafety assessment was carried out successively in full-containment greenhouse, semi-containment greenhouse, isolated field, and finally in ordinary field trials. The following items were compared between transgenic and non-transgenic cucumber plants: (1) morphological characteristics of plants and fruits; (2) reproductive characteristics, e.g. pollen morphology and fertility, longevity of the pollen, pollen dispersal by wind, and seed fertilities; (3) possibility of harmful influences on the environment due to the production of detrimental substances i.e. volatile compounds, plant parts and root secreta; (4) influence on soil microflora and; (5) presence of remaining Agrobacterium tumefaciens, which was used as a vector in the production of the transgenic cucumber. Throughout the biosafety assessment, we did not find any substantial differences except the expression of rice chitinase gene and resistance to gray mold between transgenic and non-transgenic cucumber plants.
\end{abstract}

Discipline: Biotechnology / Plant breeding

Additional key words: chitinase, genetically modified plant

\section{Introduction}

Using conventional breeding techniques of crossmating, a large number of new varieties for cultivation have been developed. However, it is laborious and timeconsuming to obtain new varieties with desirable characters by screening huge numbers of progenies. In contrast to conventional breeding, transgenic technology produces new varieties by adding only one or a few genes into commercial cultivars to overcome some fatal defects or to add new useful characters. We developed transgenic cucumber plants harboring rice chitinase gene $(\mathrm{RCC} 2)^{9}$. These plants acquired gray mold (Botrytis cinerea) resistance. RCC2 was also transferred into different crops such as strawberry, rice, and tobacco, provid-

The authors thank Dr. K. Oosawa for encouragements, Dr. S. Oka for helpful discussion and comments on the manuscript, Dr. S. Watanabe for assistance with HPLC and GC analysis and Ms. I. Kawaguchi and Ms. C. Sato for technical assistance. This work was supported in part by the grants from Ministry of Agriculture, Forestry and Fisheries.

Present addresses:

${ }^{2}$ Department of Low-Temperature Sciences, National Agricultural Research Center for Hokkaido Region

(Sapporo, Hokkaido 062-8555, Japan)

${ }^{3}$ Department of Biological Safety, National Institute for Agro-Environmental Sciences (Tsukuba, Ibaraki 305-8604, Japan)

${ }^{4}$ Department of Rice Research, National Agricultural Research Center Hokuriku Research Center (Joetsu, Niigata 943-0193, Japan)

* Corresponding author: fax +81-29-838-8397; e-mail kogaban@nias.affrc.go.jp

Received 13 March 2003; accepted 8 March 2004. 
ing resistance to bacterial diseases $\mathrm{s}^{3,6,10}$.

It is difficult for transgenic plants to acquire unintended characteristics, however, we can not affirmatively deny the possibility that transgenic plants have a harmful effect on the environment. Therefore, the overall safety assessments of the transformants have to be carried out carefully ${ }^{4}$. In Japan, biosafety assessments of transgenic plants are carried out under regulatory guidelines including four stages: (1) full-containment greenhouse (FCG) trials; (2) semi-containment greenhouse (SCG) trials; (3) isolated field trials; and (4) ordinary field trials. The assessment in FCG and SCG are carried out according to the "Guideline for Recombinant DNA Experiments" by the Science and Technology Agency ${ }^{1}$. The biosafety assessment from isolated field to ordinary field trials is done according to the "Guidelines for the Application of Recombinant DNA Organisms" by the Ministry of Agriculture, Forestry and Fisheries ${ }^{2}$.

We previously performed biosafety assessment of the transgenic melon harboring virus coat protein gene $e^{7,8}$.
We performed biosafety assessment of the transgenic cucumber plants harboring rice chitinase gene. Here, we report the biosafety assessment on transgenic cucumber in FCG, SCG and isolated field trials.

\section{Materials and Methods}

In Table 1, we listed all items for biosafety assessment. Some of these items that are not considered to have an important environmental effect, however, were excluded in this report.

\section{Plant materials and vector}

Cucumber cv. 'Shimoshirazu' from Genebank, (MAFF, Japan) was used as the original plant in the transformation experiment. Three transgenic strains (CR-29, CR-32, CR-33 $)^{9}$ which are highly resistant to gray mold were used for environmental risk assessment.

A binary vector, $\mathrm{pBI} 121-\mathrm{RCC} 2$, was constructed to replace the GUS gene of $\mathrm{pBI} 121$ with the $\mathrm{cDNA}$ of rice

Table 1. Items for biosafety assessment on transgenic cucumber

\begin{tabular}{|c|c|c|c|}
\hline Evaluation items & $\begin{array}{c}\text { Full-containment } \\
\text { greenhouse }\end{array}$ & $\begin{array}{l}\text { Semi-containment } \\
\text { greenhouse }\end{array}$ & $\begin{array}{l}\text { Isolated } \\
\text { field }\end{array}$ \\
\hline \multicolumn{4}{|c|}{ 1. Confirmation of existence and expression of introduced genes } \\
\hline (1) Existence of the selection marker gene & $\bigcirc$ & & \\
\hline (2) Existence of the rice chitinase gene & $\bigcirc$ & & \\
\hline (3) Expression of the rice chitinase gene & $\bigcirc$ & & \\
\hline (4) Resistance to gray mold disease & $\bigcirc$ & & $\bigcirc$ \\
\hline \multicolumn{4}{|l|}{ 2. Morphological and growth characteristics } \\
\hline (1) Morphological characteristics & & $\bigcirc$ & $\bigcirc$ \\
\hline \multicolumn{4}{|l|}{ 3. Reproductive characteristics } \\
\hline (1) Pollen morphology & $\bigcirc$ & & \\
\hline (2) Pollen fertility & $\bigcirc$ & & \\
\hline (3) Pollen dispersal by wind & & $\bigcirc$ & \\
\hline (4) Longevity of pollen & $\bigcirc$ & & \\
\hline (5) Seed fertility & & $\bigcirc$ & \\
\hline (6) Seed germination & & $\bigcirc$ & \\
\hline (7) Cross compatibility with allied species & & $\bigcirc$ & \\
\hline (8) Pollen scattering range & & & $\bigcirc$ \\
\hline (9) Perenniality & & & $\bigcirc$ \\
\hline \multicolumn{4}{|l|}{ 4. Production of allelochemical-like substances } \\
\hline (1) Phenolic acids produced in leaves and stems & $\bigcirc$ & & \\
\hline (2) Phenolic acids released from roots & $\bigcirc$ & & \\
\hline (3) Production of volatile compounds & $\bigcirc$ & & \\
\hline (4) Influence of soil to succeeding crop & & $\bigcirc$ & \\
\hline \multicolumn{4}{|l|}{ 5. Effect to ecosystem } \\
\hline (1) Influence on soil microflora & & $\bigcirc$ & $\bigcirc$ \\
\hline (2) Survey of flower visiting entomofauna & & & $\bigcirc$ \\
\hline 6. Residual Agrobacterium as vector & $\bigcirc$ & & \\
\hline
\end{tabular}


chitinase gene ${ }^{5}$ pBI121-RCC2 was integrated into the Agrobacterium tumefaciens LBA4404 and used as a vector.

\section{Pollen morphology, pollen fertility, and pollen longevity}

To observe pollen morphology and fertility, pollen was stained with acetocarmine. Morphological differences and stain degree of pollen were compared between transgenic cucumber and non-transgenic cucumber plants. To observe pollen longevity, pollen was placed on a media plate containing sucrose $(80 \mathrm{~g} / \mathrm{L})$, boric acid $(100$ $\mathrm{mg} / \mathrm{L}), \mathrm{Ca}\left(\mathrm{NO}_{3}\right)_{2} \bullet 4 \mathrm{H}_{2} \mathrm{O}(600 \mathrm{mg} / \mathrm{L})$, and Gelrite $(2 \mathrm{~g} / \mathrm{L})$ $(\mathrm{pH} 7.3)$ at $20^{\circ} \mathrm{C}$. Germination rate was observed after 2 , $4,6,8,10,30$, and $54 \mathrm{~h}$.

3. Detection of allelochemical-like substances using biological assay and chromatographical analysis

(1) Bioassay of allelochemical-like substances from leaves and stems

Transgenic cucumber and non-transgenic cucumber plant parts (leaves and stems) were crushed and crude extracts were prepared. The germination rate of broccoli seeds (Brassica oleracea L.) in these crude extracts was measured after one-week of incubation. Thirty broccoli seeds were used for one experiment.

(2) Bioassay of allelochemical-like substances from roots

Transgenic cucumber and non-transgenic cucumber plants were grown in soil. After two weeks growth, soil filtrate was collected. The germination rate of broccoli seeds was observed using this filtrate as previously described.

(3) Bioassay of volatile compounds

Transgenic cucumber and non-transgenic cucumber plants of 2 to 3 leaf stage were placed in plant boxes. Broccoli seeds were put on wetted paper in a dish and then placed in a cucumber plant box, closed tightly and the germination rates of broccoli seeds were scored.

(4) Chromatographical comparison of leaf and stem products

Transgenic cucumber and non-transgenic cucumber plants were crushed and extracted by ethanol, and these extracts were analyzed by high pressure liquid chromatography (HPLC). Shimadzu LC-4A HPLC with a Toso TSK gel ODS-80TM $(4.6 \mathrm{~mm} \times 250 \mathrm{~mm})$ column was employed. The separation medium consisted of solution A (acetonitrile : $\mathrm{H}_{2} \mathrm{O}:$ acetic acid $=10: 89: 1$ ) and solution $\mathrm{B}$, acetonitrile. Gradient condition was linear and flow rate was $1.0 \mathrm{~mL} / \mathrm{min}$.

(5) Chromatographical comparison of root secreta

Transgenic cucumber and non-transgenic cucumber plants were soaked and grown in distilled water. After 8 days, the water was analyzed by high pressure liquid chromatography.

(6) Chromatographical comparison of volatile compounds

Transgenic cucumber and non-transgenic cucumber plants were grown in tightly wrapped flasks. After 12 days growth the volatile phase in each flask was applied to gas chromatography using a Shimadzu GC-8A gas chromatograph. A Porapak Q $(50 / 80,3 \mathrm{~mm} \times 1 \mathrm{~mm})$ column was employed. The temperature of the sample loading chamber and column were $210^{\circ} \mathrm{C}$ and $150^{\circ} \mathrm{C}$, respectively.

\section{Effect of transgenic cucumber-cultivated soil on succeeding crop}

Cultivated soil of transgenic and non-transgenic cucumber plants were used for succeeding broccoli planting. Germination rate, plant length and fresh weight were measured at 18 days after sowing.

\section{Detection of residual Agrobacterium tumefaciens from transgenic plants}

Crude extracts of transgenic and non-transgenic cucumber were prepared in ten-fold serial dilution and spread onto $\mathrm{AB}$ medium (amounts per liter: $\mathrm{K}_{2} \mathrm{HPO}_{4} 3 \mathrm{~g}$, $\mathrm{NaH}_{2} \mathrm{PO}_{4} 1 \mathrm{~g}, \mathrm{NH}_{4} \mathrm{Cl} 1 \mathrm{~g}, \mathrm{MgSO}_{4} 300 \mathrm{mg}, \mathrm{KCl} 1 \mathrm{mg}$,

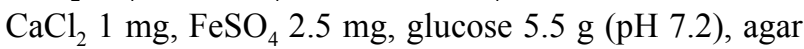
$15 \mathrm{~g})$ containing $50 \mathrm{mg} / \mathrm{L}$ kanamycin, $40 \mathrm{mg} / \mathrm{L}$ rifampicin and $500 \mathrm{mg} / \mathrm{L}$ streptomycin.

\section{Results and Discussion}

\section{Confirmation of existence and expression of introduced genes}

Three items of Table 1, (1) existence of the selection marker gene, (2) existence of the rice chitinase gene, and (3) expression of the rice chitinase gene were confirmed and reported in a previous paper ${ }^{9}$. The results of (4) resistance to gray mold disease are described below.

We examined 20 independent transgenic cucumber lines, and found three types of sensitivity to gray mold, i.e. highly resistant (non-extensible lesion), intermediately resistant (weak extensible lesion), and sensitive (extensible lesion) (Table 2). Susceptibility to gray mold infection was evaluated in terms of lesion type, which was measured 4 days after the inoculation in three independent trials.

A CR-32 transgenic plant was self-pollinated and the progenies were examined for resistance to gray mold. Out of 68 plants, resistant and sensitive plants to gray mold were 50 and 18, respectively. The result agreed statistically with a 3:1 segregation ratio of one locus trans- 
Table 2. Susceptibility of transgenic cucumber plants harboring the rice chitinase cDNA (RCC2) to Botrytis cinerea infection

\begin{tabular}{lcl}
\hline \hline Resistance & Lesion diameter $^{\text {a) }}(\mathrm{mm})$ & Transgenic cucumber strain \\
\hline High resistance & $<5$ & CR-29, 32, 33 \\
Intermediate resistance & $5-10$ & CR-1, 3, 4, 6, 8, 31, 34 \\
& & CR-15, 18, 20, 37, 42 \\
Sensitive & $>10$ & Shimoshirazu \\
& & Sagamihanjiro $^{\text {b) }}$ \\
\hline
\end{tabular}

a): Diameter of lesion was measured after 4 days of infection.

b): Non-transgenic cucumber.

Table 3. Comparison of pollen fertility* between transgenic and non-transgenic cucumber plants

\begin{tabular}{ccc}
\hline \hline & Transgenic & Non-transgenic \\
\hline Fertility (\%) & $78.1 \pm 12.0$ & $74.2 \pm 7.7$ \\
\hline
\end{tabular}

*: Pollen fertility represents stained ratio to total (ca. 200) pollen.

Data indicate average and standard deviation of 3 replications.

Table 4. Comparison of pollen longevity on media plate between transgenic and non-transgenic cucumber plants

\begin{tabular}{lccc}
\hline \hline \multirow{2}{*}{ Time of pollen collection } & Hours after sampling & \multicolumn{2}{c}{ Germination (\%) $^{\mathrm{a})}$} \\
\cline { 3 - 4 } & & Transgenic cucumber & Non-transgenic cucumber \\
\hline $7: 30$ & 0 & 29 & 36 \\
$9: 30$ & 2 & 30 & 37 \\
$11: 30$ & 4 & 38 & 41 \\
$13: 30$ & 6 & 45 & 43 \\
$15: 30$ & 8 & 37 & 34 \\
$17: 30$ & 10 & 12 & 19 \\
next day 13:30 & 30 & 16 & 5 \\
two days later 9:30 & 54 & 0 & 0 \\
\hline
\end{tabular}

a): About 200-300 pollen were employed for each time.

duction at the $1 \%$ significance level by $\chi$-square test.

\section{Morphological and growth characteristics}

\section{(1) Morphological characteristics}

Morphological and physiological characters of cucumber between transgenic and non-transgenic cucumber plants were compared. There was no obvious difference in morphological characters of leaf, stem, flower, fruit, and plant type between transgenic and non-transgenic plant (Fig. 1). There was no meaningful change in growth speed, flowering date and other developmental characters (data not shown).

\section{Reproductive characteristics}

(1) Pollen morphology

The pollen size and shape of transgenic and nontransgenic plants were found to be similar and the diame- ter of both was approximately 50-60 $\mu \mathrm{m}$ (Fig. 2).

(2) Pollen fertility

The difference in pollen fertility was measured by staining with acetocarmine. There was no meaningful difference between transgenic and non-transgenic cucumber in pollen fertility (Table 3 ).

(3) Pollen dispersal by wind

The array of 10 pots of transgenic plants was placed $50 \mathrm{~cm}$ apart from the array of 8 pots of non-transgenic plants and possible spontaneous pollinations between them were examined. After 35 days of flowering, cucumber plants were harvested to examine the seed setting. No seed setting was found in transgenic or nontransgenic cucumber plants. It is common for entomorphilous flowers not to set seed in a closed greenhouse without insects. 


\section{(4) Longevity of pollen}

Pollen was put on media plates and the germination rate was observed after 2, 4, 6, 8, 10, 30, and $54 \mathrm{~h}$ (Table $4)$. There was no difference between transgenic and nontransgenic cucumber in pollen germination rates.

(5) Seed fertility

Seeds of crossed flowers were obtained after maturation of cucumber fruits. The yield in number of transgenic cucumber plant seeds was similar to that of nontransgenic cucumber plants (data not shown).

(6) Seed germination

Seed germination rate was almost $100 \%$ and there was no difference between transgenic and non-transgenic cucumber seeds.

(7) Cross compatibility with allied species

Transgenic and non-transgenic cucumber plants were crossed with allied species (Cucumis melo L., $C$. anguria L., C. figarei Del. ex Naud.) and no cross hybrid seeds were obtained.
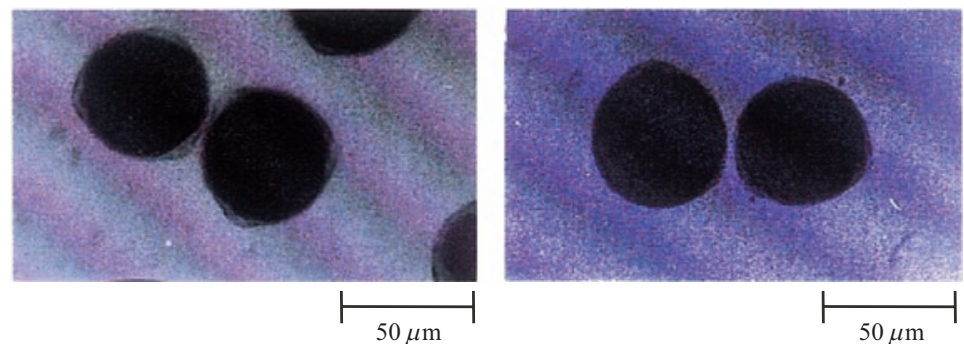

Fig. 2. Pollen of transgenic cucumber (left) and non-transgenic cucumber (right)

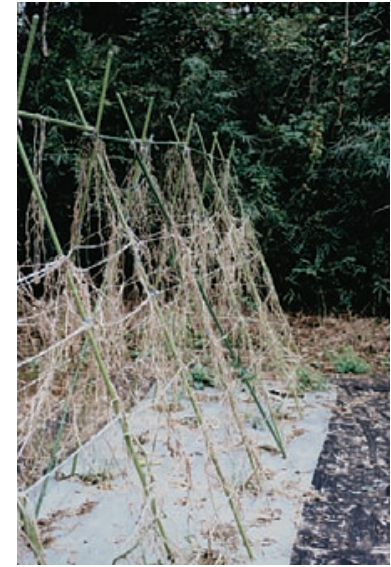

Transgenic cucumber

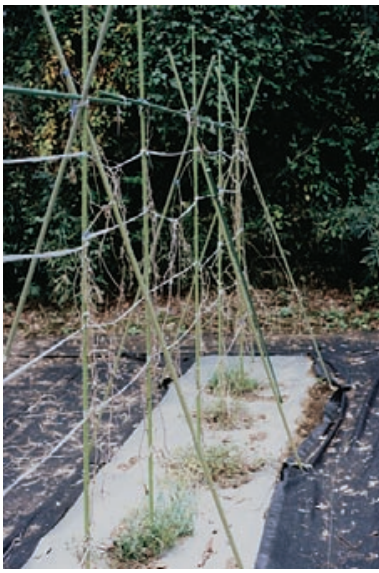

Non-transgenic cucumber
Fig. 3. Overwintering ability experiment in the isolated field trial

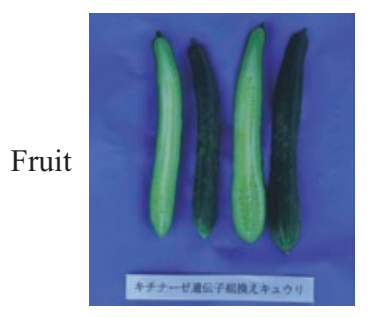

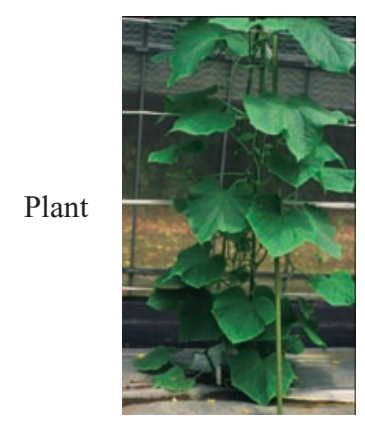

Transgenic (A)

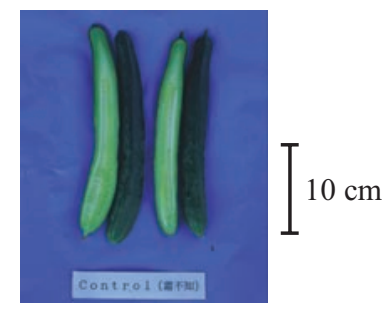

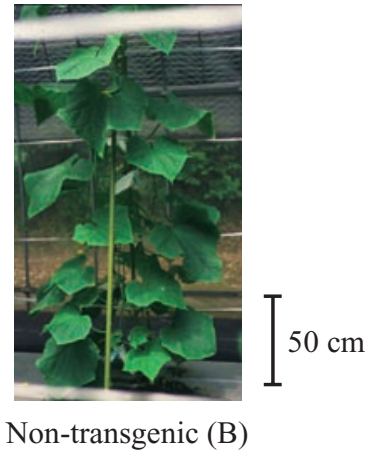

Fig. 1. Comparison of fruit and plant of transgenic (A) and non-transgenic (B) cucumber 
(8) Pollen scattering range

Pollen scattering range was determined at the isolated field trail. There were no differences between transgenic and non-transgenic cucumber plants in pollen scattering range (data not shown).

(9) Perenniality

Perenniality of transgenic plants is very important for examining its weediness. We examined overwintering ability of cucumber plants in the isolated field trail and cold tolerance of cucumber seedlings in a growth chamber.

Both transgenic and non-transgenic cucumber plants withered in November after harvesting fruits in the isolated field trail (Fig. 3). Therefore, it was confirmed that neither transgenic nor non-transgenic cucumbers show overwintering ability.

Seedling plants of transgenic and non-transgenic cucumber treated at $4^{\circ} \mathrm{C}$ for one week did not have cold tolerance (Fig. 4).

\section{Production of allelochemical-like substances}

(1) Phenolic acids produced in leaves and stems

Allelochemical-like substances of plant leaves and stems were measured by the broccoli germination rate. Germination rates were 99.2\% (transgenic) and 99.6\% (non-transgenic). Employing the t-test indicates no significant difference between transgenic and non-transgenic cucumber plants (Table 5).

Chromatograghical comparison of leaves and stems was also performed. HPLC data of transgenic and nontransgenic leaf extracts showed very similar signal profiles in peak position and peak form (Fig. 5). Although there were minor differences in peak height, we concluded these were the result of individual divergence as individual plants showed similar minor differences.

(2) Phenolic acids released from root

Allelochemical-like substances secreted from roots were measured by broccoli germination. Germination rates of broccoli in transgenic and non-transgenic cucumber root secreta were $91.2 \%$ and $93.2 \%$, respectively. Employing the t-test indicates no significant difference between transgenic and non-transgenic cucumber plants (Table 5).

Chromatograghical comparison of root secreta was also carried out. Transgenic cucumber and non-transgenic cucumber roots were soaked and grown in distilled water. After 8 days, the water was analyzed by high pressure liquid chromatography (HPLC). HPLC data of transgenic and non-transgenic cucumber root secreta also showed almost the same signal profiles. There were also minor differences, which we attributed to individual divergence (Fig. 6).

(3) Production of volatile compounds

Effect of volatile compounds was measured by the germination rate of broccoli in an airtight plant box containing cucumber plants. Germination rates of broccoli in the plant boxes with transgenic or non-transgenic cucumber plants were $98.0 \%$ and $98.4 \%$, respectively. Employing the t-test indicates no significant difference between transgenic and non-transgenic cucumber plants (Table 5).

Chromatograghical comparison of volatile compounds was also performed. The elution profile of volatile compounds from transgenic and non-transgenic cucumber plants was compared by gas chromatography (Fig. 7). The gas chromatography data of transgenic and non-transgenic cucumber plants also showed no meaningful difference in the peak position and peak form.

(4) Effect of transgenic cucumber-cultivated soil on the growth of succeeding cultivated crop

To evaluate the impact of cultivated soil, broccoli was cultivated again using the same soil. No significant differences in germination rate and seedling growth of broccoli were observed in soils in which transgenic or non-transgenic cucumber had been grown (Table 6).

Table 5. Influence of biological products of transgenic or non-transgenic cucumber plants on broccoli germination

\begin{tabular}{lcc}
\hline \hline \multirow{2}{*}{ Growth condition } & \multicolumn{2}{c}{ Germination percentage } \\
\cline { 2 - 3 } & Transgenic & Non-transgenic \\
\hline Plant extracts & $99.2 \pm 1.1$ & $99.6 \pm 0.9$ \\
Root secreta & $91.2 \pm 6.1$ & $93.2 \pm 5.4$ \\
Volatile compounds & $98.0 \pm 2.0$ & $98.4 \pm 2.4$ \\
\hline
\end{tabular}

No significant difference was detected by t-test in all growth conditions.

Data indicate average and standard deviation of 3 replications. 


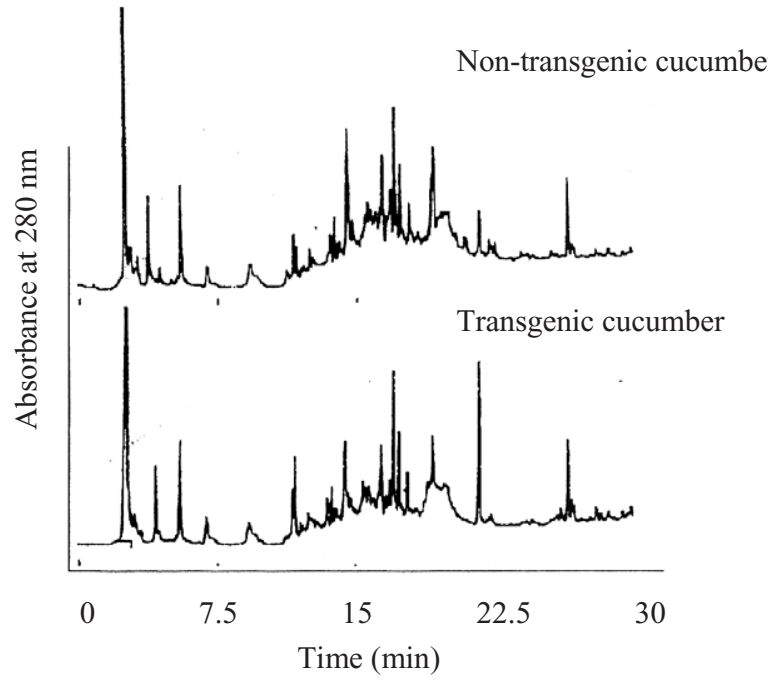

Fig. 5. Elution profile of leaf extracts from transgenic and non-transgenic cucumber plants by HPLC

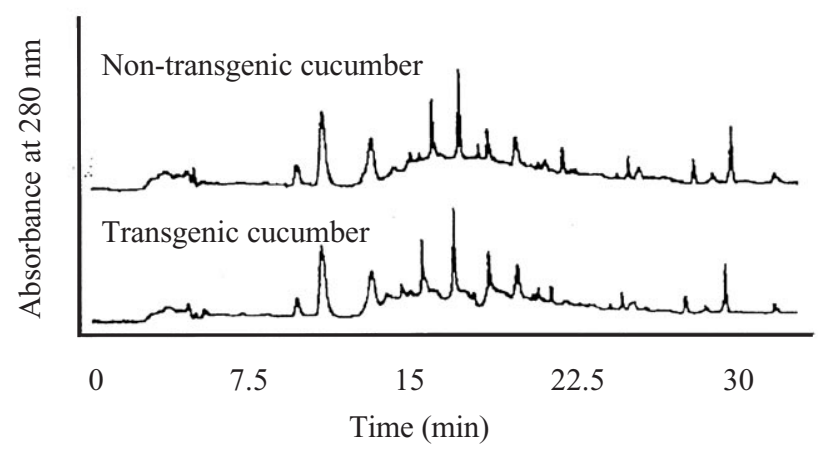

Fig. 6. Elution profile of root secreta from transgenic and non-transgenic cucumber plants by HPLC

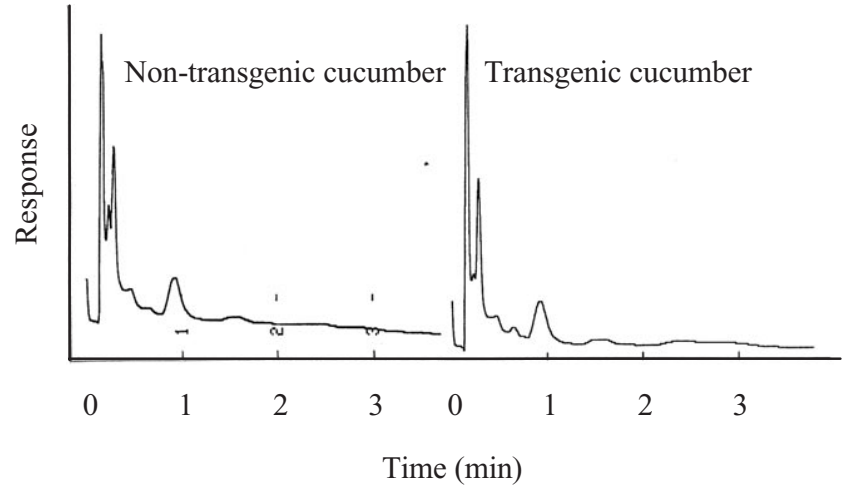

Fig. 7. Elution profile of volatile compounds from transgenic and non-transgenic cucumber plants by gas chromatography

\section{Environmental effect}

(1) Influence on soil microflora

Number of microorganisms in the soil, in which transgenic or non-transgenic cucumber plants were grown, is indicated in Table 7. Number of bacteria and actinomycetes in non-transgenic cucumber-cultivated soil was a little larger than that in transgenic cucumbercultivated soil. Number of fungi was found to be vice versa. However, the values were quite similar and we considered that transgenic cucumber cultivation had no effect on soil microflora.

(2) Survey of flower visiting insects

Flower visiting insects at the transgenic and nontransgenic cucumber field was determined using an insect trapper. Insect trappers were located in the transgenic and non-transgenic cucumber field and the species of

Table 6. Seed germination and seedling growth of broccoli planted in the soil in which transgenic and non-transgenic cucumber had been previously grown

\begin{tabular}{lccc}
\hline \hline Soil origin & $\begin{array}{c}\text { Germination } \\
(\%)\end{array}$ & $\begin{array}{c}\text { Plant length } \\
(\mathrm{cm})\end{array}$ & $\begin{array}{c}\text { Fresh weight of } \\
\text { seedling }(\mathrm{g})\end{array}$ \\
\hline Transgenic cucumber & $93.3 \pm 1.2$ & $9.8 \pm 1.2$ & $24.7 \pm 2.1$ \\
Non-transgenic cucumber & $94.0 \pm 2.0$ & $9.6 \pm 1.0$ & $25.5 \pm 1.8$ \\
\hline
\end{tabular}

Data indicate average and standard deviation of 4 replicates with each 50 samples.

Table 7. Number of microorganisms in the soil in which transgenic or non-transgenic cucumber plants were grown

\begin{tabular}{lccc}
\hline \hline Soil origin & \multicolumn{3}{c}{ No. of microorganisms (CFU/g soil) } \\
\cline { 2 - 4 } & bacteria & actinomycetes & fungi \\
\hline Transgenic cucumber & $8.6 \times 10^{6}$ & $1.3 \times 10^{5}$ & $1.4 \times 10^{4}$ \\
Non-transgenic cucumber & $9.6 \times 10^{6}$ & $1.8 \times 10^{5}$ & $1.2 \times 10^{4}$ \\
\hline
\end{tabular}

Numbers of microorganisms are the averages of the counts from 5 plants. 


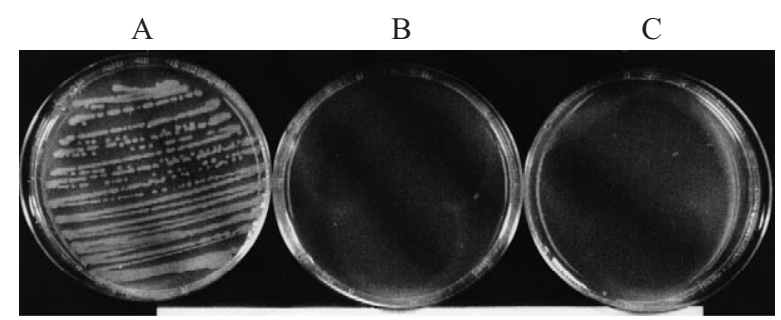

Fig. 8. Detection of residual Agrobacterium tumefaciens used for transformation

A: Agrobacterium tumefaciens. B: crude extracts from transgenic cucumber. C: crude extracts from non-transgenic cucumber.

flower visiting insects were identified. Visiting insects were mainly Hymenoptera (Apis cerana Fabricius, Scolia decorata ventralis Smith), Diptera (Megaspis zonata Fabricius), and some Lepidoptera (Parnara guttata Bremer \& Grey). There was no difference in flower visiting insects between transgenic and non-transgenic cucumber.

\section{Residual Agrobacterium as vector}

There was no agrobacteria growth from crude extracts of transgenic and non-transgenic cucumber (Fig. 8 ), but agrobacteria was found to grow on the same media. Transgenic cucumber does not harbor Agrobacterium.

\section{Conclusion}

We carried out a biosafety assessment of the transgenic cucumber harboring rice chitinase gene in full-containment greenhouse, semi-containment greenhouse and isolated field trials. All these assessment data indicate no obvious difference between transgenic and non-transgenic cucumber plants. The difference is only gray mold resistance between conventional non-transgenic cucumber and rice chitinase gene transformed transgenic cucumber. Therefore, we conclude transgenic cucumber plants have no acquired new characters which affect the environment.

\section{References}

1. Asao, H. et al. (1997) Enhanced resistance against a fungal pathogen Sphaerotheca humuli in transgenic strawberry expressing a rice chitinase gene. Plant Biotech., 14, 145-149.

2. Kjellsson, G. \& Simonsen, V. (1994) Methods for risk assessment of transgenic plants. Birkhauser Verlag, Basel, pp.214.

3. Life Science Division, Science and Technology Agency (STA) (1992) Kumikae DNA jikken shishin [Guideline for recombinant DNA (rDNA) experiment]. STA. Tokyo, Japan, pp.245 [In Japanese].

4. Ministry of Agriculture, Forestry and Fisheries (MAFF) (1992) Norin suisan bunyani okeru kumikaetai no riyounotame no shishin [Guidelines for the application of recombinant DNA (rDNA) organisms]. MAFF, Tokyo, Japan, pp.67 [In Japanese].

5. Nishizawa, Y. et al. (1993) Sequence variation, different expression and chromosomal location of rice chitinase genes. Mol. Gen. Genet., 241, 1-10.

6. Nishizawa, Y. et al. (1999) Enhanced resistance to blast (Magnaporthe grisea) in transgenic rice by constitutive expression of rice chitinase. Theor. Appl. Genet., 99, 383-390.

7. Tabei, Y. et al. (1994a) Environmental risk evaluation of the transgenic melon with coat protein gene of cucumber mosaic virus in closed and semi-closed greenhouse (I). Breed. Sci., 44, 101-105.

8. Tabei, Y. et al. (1994b) Environmental risk evaluation of the transgenic melon with coat protein gene of cucumber mosaic virus in closed and semi-closed greenhouse (II) Breed. Sci., 44, 207-211.

9. Tabei, Y. et al. (1998) Transgenic cucumber plants harboring a rice chitinase gene exhibit enhanced resistance to gray mold (Botrytis cinerea). Plant Cell Rep., 17, 159-164.

10. Takatsu, Y. et al. (1999) Transgenic chrysanthemum (Dendrathema grandiflorum (Ramat.) Kitamura) expressing a rice chitinase gene shows enhanced resistance to gray mold (Botrytis cinerea). Sci. Hort., 79, 113-123. 